\title{
Unequal Conditions: A Systematic Review of the Relationship between Urban Poverty and Psychological Resilience
}

\author{
Angélica Ojeda García ${ }^{1, *}$, Bernardo Turnbull Plaza ${ }^{1}$, Jaime Fuentes Balderrama ${ }^{1}$, \\ Cinthia Cruz del Castillo ${ }^{1}$, Alison K. Cohen ${ }^{2}$ \\ ${ }^{1}$ Department of Psychology, Universidad Iberoamericana, Mexico City, Mexico
${ }^{2}$ Department of Public and Nonprofit Administration, School of Management, University of San Francisco, United States
}

Copyright $\mathrm{O} 2019$ by authors, all rights reserved. Authors agree that this article remains permanently open access under the terms of the Creative Commons Attribution License 4.0 International License

\begin{abstract}
Poverty is one manifestation of inequality: it is often a consequence of an unequal distribution of social resources, especially in urban settings. The lack of resources can impact people's quality of life and provoke a spiral that reinforces the cycle of poverty. The concept of resilience can be a useful framework for understanding a person's positive adaptations to urban poverty's environmental stressors. This paper seeks to comprehensively understand how urban poverty influences the social functioning and well-being of individuals in urban areas. We conducted a systematic review to identify the risk factors that limit or increase vulnerability and the resilient responses that promote development and psychological functioning among those experiencing urban poverty. We explore how resilience can help overcome the vulnerabilities urban poverty creates and identify the coping strategies some families experiencing urban poverty use. We encourage researchers and practitioners to take a strengths-based approach to understanding individuals' resilient responses and community involvement as they socially adapt to unequal conditions in diverse and myriad ways.
\end{abstract}

Keywords Inequality, External Stressors, Psychological Resilience, Systematic Review, Urban Poverty

\section{Introduction}

This paper seeks to comprehensively understand how urban poverty affects the social functioning and well-being of individuals in urban areas. Then, this systematic literature review explores the relationship between urban poverty and psychological resilience. We begin by conceptualizing resilience and urban poverty. Building upon the operational definition of poverty and its impact on the functioning and social adaptation of those who live in urban areas, we explore how resilience can help overcome the limitations of experiencing poverty and how these two forces can interplay such that resilience can emerge from within a set of vulnerability.

\subsection{Conceptualizing Resilience}

The concept of resilience is used across many disciplines, including public health, education, social welfare and psychology. Drawing from positive psychology, we conceptualize resilience as a cross-cutting characteristic that affects how a person responds to adversity and/or risky environments in a way that leads to thriving cognitively and/or emotionally, despite the circumstances [1-2]. This can be a stage or a domain, if it integrates salient skills and abilities, or it can be an adaptation process in which an individual accumulates protective factors that modify how they respond to urban poverty's environmental stressors over time [3]. It is a dynamic concept, which includes proximal and distal stressors, short- and long-term outcomes, and oscillates vertically from individual, familial, social, community until ecological level and horizontally from personal, interpersonal, group or systemic condition [4]. Resilience allows someone to go beyond adversity and re-attain control over the situation, and provides a strengthened mental state, higher maturity, emotional stability, and resistance to endure what comes next [5]. Resilient individuals can be self-confident, achieve success, and feel life satisfaction and wellbeing regarding any life condition the person encounters. A resilient person can flow and seek integral development. In fact, resilience builds upon different models of human development [3]. There are some researchers that consider 
resilience a relational skill, because it directly connects risks and stressors with those cognitive functions related to a coping responses [6], and any kind of this mental capacities are considered as protective factors [7]. Then, it is called "psychological resilience".

\subsection{Conceptualizing Urban Poverty}

Poverty implies a condition of vulnerability due to limited resources. For the purposes of this review, we consider poverty as synonymous with "low-income", with the understanding that limited financial resources limit one's ability to a) meet basic needs and b) have access to resources (e.g., education, health services, social capital) that can improve one's quality of life (e.g., self-confidence, self-assurance in undertakings and life satisfaction in the psychological real) [8]. Family income can affect the acquisition of protective resources willing the basic needs and respond to social inequality [9]. Low-income households can reduce risk and secure their livelihoods, potentially leading to escaping poverty [10-13].

According to the INEGI [Mexican National Statistical, Geography and Information Institute, 14], urban poverty is substantively different from poverty in rural areas and requires building new conceptual frameworks that recognize its multidimensional nature [15]. Urban poverty includes poor quality housing, service provision, living environments and health outcomes $[16,17]$.

In our conceptualization of urban poverty, we acknowledge the divide between actor-oriented frameworks for understanding lack of income and assets for one side [18], which includes concepts like 'livelihoods', 'vulnerability', 'capabilities' and 'assets' [19], 'capitals', [18], or 'endowments' [19]. Urban poverty can also be understood as a manifestation of inequalities within a society: there are typically enough resources within a given urban area, but the unequal distribution of those resources creates a subpopulation experiencing urban poverty. Inequalities are maintained through hierarchical forms of authority and power. Political inequalities at the city or town level create, maintain, and exacerbate poverty and inequality. These inequalities allow a small elite to dominate resource distribution among low-income urban households, restricting access to the most valuable social resources that support social and economic advancement [18].

\subsection{Poverty in Relation to Psychological Resilience}

Poverty can affect an individual's psychological wellbeing via adaptation processes. Those who live in poverty are socially disadvantaged due to disparities in resource allocation (principally physical, services, employment and health) within societies [8]. The lack of resources and living in high-risk circumstances can take a toll and sometimes generate unexpected and inappropriate responses to stressors; these typically impulsive or immature responses include expressing symptoms of anxiety or stress. The symptoms of anxiety are natural responses to poverty, but in the urban poverty condition, they were expressed as consequence but not to acting to diminish the external stressors or control them. In other times, these give the person energy to search the changed [20-21].

When financial resources are limited, there is a risk of having a self-perpetuating negative feedback loop between environmental risks experienced by someone negatively adapting to living in urban poverty. This can manifest in a few different ways, including disproportionate reactions to risks as people draw upon their prior risk exposures when determining how to respond, focusing on getting back to their previous state by returning to routines, or attempting to tackle the root causes, counteracting and overcoming the risks to try to overcome poverty. No response is also possible if the person does not have the resources and does not realize the risk in the present situation or recognizes the lack of resources to face the situation. The person can in turn be overwhelmed to such a degree in which cognitive deconstruction, emotional sickness, or somatization occurs [22].

In turn, living in a context of urban poverty can lead to developing a sense of entrapment in a context ridden by oppression, marginalization, desolation, abandonment, social expulsion and/or exclusion by socioeconomic disadvantage, which can affect whether or not someone responds resiliently [23-24]. The common denominator in such situations is the vulnerability a person experiences, by not having access to options to meet basic needs in order to achieve wellbeing and a decent quality of life.

In conclusion, the link between urban poverty (from this point on, UP) and resilience may reflect disparities in psychological, behavioral, emotional and cognitive resources to adequately respond to challenges that arise from conditions of poverty [3,23]. As study variables, both are immersed in a dynamic in which people that live in this condition are exposed to diverse risks (social, personal, family and community) and/or refer adverse backgrounds during their development. We emphasize that it is important to think about urban poverty as an environmental risk that is not the fault of an individual, but a structural condition that individuals may experience, and which individuals often see as part of their everyday life [25]. They may respond to poverty according to their self-assessment in terms of the magnitude of the threat, then their own resources and anyway (i.e., behavioral, cognitive, emotional). Our research questions seek to understand the relationship between UP and resilience as a psychological concept.

\subsection{Purpose of This Review}

We had two main research questions: 1) Which are the 
risk factors that limit or increase vulnerability, and which are those resilient responses toward positive development and psychological functioning among those who live in UP? and 2) What combination of resilient factors give families and individuals the possibility of escaping urban poverty, expressing psychological functioning, and/or positively adapting socially?

\section{General Objective}

Understand the relationship between UP and the resilient behavior in terms of cognitive and psychological responses, as resilient indicators in urban people in metropolitan areas.

\section{Specific Objectives}

In order to guide our review, we developed a typology of three domains in relation to the context of UP and their resilient or non-resilient responses, and identified the following specific objectives:

1. Understand how people respond from their income-limited condition.

2. Distinguish life skills as resources to cope with poverty and social adaptation.

3. Characterize how people experiencing urban poverty respond to adverse situations and develop and express resilience.

\section{Method}

\subsection{Strategy in the Building Data}

We conducted our present systematic review following 5 steps [26]: defining research questions and then corresponding search engines and algorithms, inspecting the resulting abstracts, summarizing the evidence, and analyzing it. The revision was performed in two search engines: Web of Science and EBSCO. The search period was from 1990 (year in which the term resilience was coined by Rutter) [27] to 2016 (for practicality concerns). The keywords were based on the terms resilience, UP and their derivatives. We used a Boolean search process that was conducted in the same way in English and Spanish for EBSCO and Web of Science: (Title and Abstract: urban $O R$ semiurban OR periurban OR "inner city" OR city $A N D$ Theme: poverty OR poor OR low-income OR vulnerability) AND (Theme: "resil*" NOT Theme: ecology NOT Theme: environmental NOT Theme: economic NOT Theme: education) and (Título y Abstract: urbana OR semiurbano OR semiurbana OR periurbano OR periurbana OR ciudad AND Tema: pobreza OR "bajo ingreso" OR vulnerabilidad OR marginados) AND (Tema: "resil" " NOT "Ecol*" NOT ambiental NOT "económica OR económico" NOT educación). We restricted the search to peer-reviewed journal articles reporting original research, eliminating grey literature.
Out of the articles resulting from the algorithms ( $\mathrm{n}=422)$, after a first filter, 324 articles were eliminated for the following reasons: (i) Articles with themes not related to the object of study $(\mathrm{n}=52)$, (ii) articles related to non-psychological resilience (e.g., ecological resilience $(n=69)$, economic resilience $(n=5)$, (iii) articles about natural and technological disasters ( $\mathrm{n}=45$ ), (iv) engineering and urban planning centered articles $(\mathrm{n}=48)$, (v) articles on academic performance $(\mathrm{n}=12)$, (vi) articles about food security ( $\mathrm{n}=5$ ), (vii) specific themes that were not related to the object of study such as migration, cancer or neurological diseases $(n=23)$, (ix) workplace of hospital based articles $(n=17),(x)$ rural based studies $(n=6),(x i)$ duplicates $(\mathrm{n}=2)$, (xii) meta-analyses about resilience topic $(n=3)$ and (xiii) articles that they did not consider poverty in relation to resilience $(n=37)$. The articles were reviewed by two members of the research team.

The remaining 98 articles were subsequently analyzed in order to assess their methodological quality and connection to the research questions that had been initially proposed. In order to carry out the assessment, we established specific quality criteria for quantitative and qualitative methodologies, drawing from guides developed by others [28]. This, in turn, led to the exclusion of 71 articles. Fifty-one articles were excluded for the same reasons identified above. The rest were methodologically inappropriate for this paper in terms these not specified the sample or this was only with three or study per case $(n=6), 2$ were in Portuguese although the abstract was in English, 16 did not describe the relationship between UP and resilience, and 2 more were inaccessible (it is feasible that they were congress summaries edited in a journal).

The majority of the reviewed articles $(n=13,48.14 \%)$ can be found in journals classified within health and medicine, followed by journals of social sciences and humanities $(\mathrm{n}=11,40.74 \%)$, and politics and government journals $(n=3,11.11 \%)$. This suggests that the relationship between UP and resilience is being studied most by health researchers.

Most of the research conducted on UP in relation to resilience was in North America ( $\mathrm{n}=18 ; 66.6 \%$ of the articles reviewed). The rest are distributed in Latin America and the Caribbean ( $\mathrm{n}=5)$, Africa $(\mathrm{n}=3)$, and Asia $(n=1)$. Most of the research was done in high- or mid-high-income countries; only 4 studies were done in low- or mid-low-income countries. The regions with less research (e.g., Latin American, Africa, Asia) are those that report higher levels of UP and so could most benefit from the research. We posit that this is likely due to limited resource availability to conduct research and publications, rather than limited interest of researchers to study these themes.

\subsection{Study Approaches of Articles Reviewed}

Most (74\%) of the studies used quantitative methods 
and showed a clear link between resilience and urban poverty, which can activate different possibilities and a person's internal and/or external resources (called protective factors) to achieve resilience. The qualitative studies were $26 \%(n=7)$ used a variety of methodological techniques, including: in-depth or semi-structured interviews and phenomenological studies to understand the resilience context from narratives, meanings and symbolisms that the participants use to portray their experiences, which has contributed in understanding the qualitative aspects of intensity, frequency, impact, type of UP and resilience [29-30].

Some of the ways in which risk and protective factors were measured include: family socialization, family functioning, parental monitoring, family agreements, family belief, communication and organization system, social support network as coping responses, social competences and communal strength, not only in response to external stressors, but in a manner in which the person could find a solution and give way to a possibility for development.

\subsection{Data Analysis}

The resulting 27 articles were retained as our dataset for the purposes of this systematic review. We generated categories and subcategories in relation to the types of risk and protection factors reported in the article pool that are helpful in addressing the description of the relationship between UP and resilience as seen from an individual, family and community settings. We then explored how these three levels in which poverty and resilience interact and consequently ease or obstruct the enhancement and development of psychological functioning of people that live in an UP context by describing how life trajectories are affected as a response to their economic condition.

\section{Results}

We summarize our findings, organized to respond to our research questions and specific objectives.

\subsection{Measuring Urban Poverty}

The studies measured urban poverty in different ways, and often discussed the presence of risk factors common to UP neighborhoods as well [8, 20, 31-34]. For example, the samples included slums and charitable organizations for vulnerable groups that were identified by national indices on income [2, 35-38]. Others documented common behaviors associated with low-SES neighborhoods in urban or peri-urban zones (i.e. drug abuse, alcohol use, illicit behavior, delinquency and violence) $[23,39]$.

In our pool of studies reviewed, children and adolescents were the most common population studied. The $74 \%(n=20)$ of studies that evaluated children and adolescents mostly interviewed participants in public schools or in public housing. There, UP is more than a conceptualization documented by the literature, is defined by the praxis and the neighborhood's income status. Its impact can affect all lifecycle stages. Income is the form the people connect to their UP condition. For this review, in response to our first specific objective, the majority of articles described the condition of UP based on national censuses, homelessness, samples resided in slums or poor neighborhoods, children went to public schools, and/or families received some sort of government subsidy.

\subsection{Measuring Resilience}

Resilience is the psychological variable that integrates all possible behaviors and capabilities a person can access to break a reinforcing circle (caused by habituation), and those developed by re-signifying their own experience, derived from any vulnerability conditions. Being resilient means not only resisting stress [40], but also growing by facing adverse situations like urban poverty [23]. One study reported that being resilient is becoming more aware of their condition, because the conscience level may motivate the person to leave it [3]. Therefore, it is essential to distinguish not only who is more resilient, but also to identify how people in UP conditions exert their resilient capabilities as a way to face their everyday life.

These studies used different indicators of resilience such as cognitive capacities or social skills, including: self-esteem [31], subjective well-being, individual competences and social resilience [32,40], coping strategies $[20,23,38]$, social support and religious beliefs $[20,36,41]$, social cohesion and trajectories of resilience [3], relationships parent-child and family's characteristics [37], adaptive responses [8,34], social adjustment response [39], sense of belonging [25,43], and close relationship with one adult as resilience responses in children [24, 33, 45], family cohesion [30,33], and community resilience [33]. In particular, among resilience responses in children, they an express symptoms internalizing (some signs of anxiety or depression as problems to sleep, social isolation) [40] and some behavior externalizing such as: problems of behavior at school [42], sense of exclusion, displacement or abandonment [2], deviant behavior. Among authors reviewed, one in particular referred that the community disorder as the all kind of violence we can see for the streets and graffiti as structural context which affects the resilience responses in urban poverty people. Therefore, of the above cognitive and social aspects of a person are ways of expressing resilience and, at the same time, are ways of dealing with urban poverty, regardless of the type of need to which they have to respond. Few articles observed the same variables, indicating the diversity and complexity of resilience responses.

\subsection{Approaches for Measuring UP and Resilience}

We analyze the articles focused on observing just what 
these psychological-cognitive processes in a context of economic disadvantage we can distinguish those psychological factors that diminish adaptive behaviors and can block progressed development and try to get out from urban poverty. The psychological skills can be the base to induce positive adaptation, opportunities for development, and search the access to resources. The concept of resilience is a dynamic construct, varies at multiple and vertical levels (e.g., individual, familial, social, community, system), at the same time, it is expressed in different horizontal ways such as personal, interpersonal, and group relationships [4]. In relation with urban poverty, this (UP) as construct can be defined in two conceptually different ways $[15,46]$ : lacking income, or lacking possibilities to act due to limited assets, capabilities and resources $[19,47]$. So, for either approach, it makes more sense to measure UP at a household level rather than at an individual level [46]. Therefore, a combination of physical, natural, human, financial and social capitals can provide a base through which low-income households can reduce risk and secure their livelihoods, potentially leading to escaping poverty.

However, there is a tendency to stigmatize UP. The lack of resources to respond to UP can be a risk factor for negative health and wellbeing outcomes, generating externalizing and internalizing symptoms. In response to this, there are certain variables that could be named "resilient responses" at an individual level: Intelligence, impulse control and social skills [40], interpersonal skills, organizational skills, conflict resolution, social connection, and an individual perception of family support $[2,28,35-36,40]$. In the articles reviewed, many different variables were used as indicators of resilience, suggesting the choice of each one was driven by the authors' theoretical perspectives.

\subsection{Exposure to Community Violence as Proximal Risk Factor Most Associated to the Condition of UP}

Community exposure to violence was a risk factor that impacts a many negative outcomes, examples of this including: drug abuse [21,23,39,48], delinquency, illegal behaviors, drug dealing, weapon dealing and risky sexual behavior [21,23,39], vandalism-related trauma and safety perception [48], having being a victim or a witness of violence $[3,48]$ is called community disorder for them. In addition, two more recent articles considered poverty itself as a risk factor [21,38] because can generate non-adaptive responses. The first focused on unemployment and economic disparity and the second focused on homelessness. Perspectives of whether or not community disorder (above explained) was modifiable ranged; most argued for helping to develop social and community resilience through awareness, parental involvement, and community cohesion from family or civil organizations $(n=9)[3,20,21,23,31,33,39,42-43]$, but one paper argued that it is impossible to resolve but remains highly influential [40]. In addition to community violence more generally, another risk factor mentioned was domestic violence, which affects familial structure and psychological outcomes [42, 49].

\subsection{Community Disorder in Neighborhoods as a Proximal Stressor Everyday}

In the more positive counter framing, social or community cohesion is understood as a resilient response and a protective factor in relation to the reduction of violent behaviors, drug and alcohol use as well as non-adaptive behaviors in the neighborhood $[3,23,31-35$, $39,42,44,48]$. A cohesive environment will offer its members the sense of belonging, the value in realization [24], religious beliefs, social inter-relation skills, to develop a support network [24, 32, 34-36, 37-38, 40] offer models to solve conflicts $[1,24]$ and socially adaptive responses [8, 34]. There are two more articles that reference the opposite occurrence by stating that when there is no community disorder, it is impossible for the actors to generate resilient behaviors or responses towards the environment $[33,39]$. With this kind of consequences, the people leave to improve your psychological development and keep inside the cycle of poverty.

\subsection{Physical Manifestations of Community Disorder}

Only one study focused on the physical setting of UP communities [39]. The physical disorder such as abandoned property, graffiti, garbage as condoms, syringes or bullet holes used on the streets is negatively related to resilience response, then they can produce non-adaptive behaviors [39,43-44]. These authors call it physical disorder, which refers to the physically visible. Physical disorder is also called neighborhood disorder [43-44]. This physical disorder is negatively related to resilience. All communities have some options to response to violence from resilient coping skills, with: neighborhood functioning [3], neighborhood efficacy also referred as community cohesion [23], community and social support $[31,33,35,50]$ and resource network [1] can be configured. This resource network does not only consider community, friendship and family bonds, it refers to other types of resources such as county or government resources, access to employment, work benefits, afterschool services [34] and medical services [30].

\subsection{The Relation between Community Disorder and Family Disorder}

Social and community disorder is also related to family factors when the lack of economic resources, the breadwinner's employment, and low emotional and 
psychological resources might lead to poor parental monitoring and low communication with children and adolescents in the household. Similarly, the null or low supervision parents have on their children is related to teenage pregnancy (which is a health risk for teenagers), which in turn is related to school drop-out rates [23]. In this context of disorganization and disorder, there is a coexistence of the variables whose are called as stressors and quotidian problems $[30,32,41]$ derived from community or neighborhood violence [39]. The size or intensity of these stressors and problems depend on the individual's perception of them [44].

\subsection{Family Functioning as a Background Condition}

In the category of background conditions, many articles mention some aspects of the family context, likely because of its strong potential for influence on individuals' lives $[24,31,35,38]$. These familial factors included: exclusion, displacement, abandonment, religious or political recruitments [2, 37]; perception of negative events, anxiety or depression in family [40]; deviant behavior among peers, family and community [34] and low-quality family structure, organization, cohesion [30]. Although family as a theme can be looked at much more broadly, the different studies used variables such as: parental divorce [24], single parent households [43], relationship and communication between parents and children-parent interactions [37, 48], parental well-being [37], inadequate parenting consisting of poor discipline practices with poor parental warmth [30], and poor parental supervision [24, 30]. Two more do not see it as an issue exclusive to the family setting, the peer and community influence ought to be observed too [34], and there is the matter of household overcrowding [22]. Among other adverse background conditions, there was a qualitative article that considered previous experience with stories about living on the streets and political/religious recruitment to belong to gangs [2], as well as aspects related to health and nutrition [24].

\subsection{Resilience as a Strategy for Managing Urban Poverty, in Specific the Most Common Factor: Community Violence}

This systematic review revealed that 19 out of the 27 analyzed articles $(70.3 \%)$ reported selecting their sample by using at least one risk factor or at least one adverse background condition as an inclusion criterion $[3,23,20-21,31,33,39,42-44]$. Although the authors do not specify or provide a clear distinction between a risk factor and an adverse background condition, the latter is seen more as a product of personal history that affects personal development and maturity, and will therefore be understood this way for this review. In this sense, exposure to community violence was an indicator of disadvantage or adversity in 10 analyzed articles.

\subsection{Protective Factors in UP Context to Promote Resilient Behaviors}

The 7 qualitative articles operationalize resilience as a dependent variable, focusing on how UP affects social-emotional aspects that are related to resilience, including social adaptation[31-32], favorable social behavior [32] manifested by a series of social competencies: self-confidence [33], positive self-concept, capacity for flexibility, possess organizational skill, problem resolution skills [8], autonomy, humor, creativity, self-esteem, empathy [45], possess family, guardian or community support $[33,36]$, have the ability to socially connect and develop interpersonal relationships [8] have a social network [32, 36], and reside in a positive neighborhood [33]. Three articles in particular focus on the influence of the family system $[7,30,32]$, given that the protective factors come from the system of beliefs the family has, organizing patterns, structure, communication, routines, cohesion, parental practices, quality of relationships, and coping skills. Two other articles $[32,36]$ also emphasize the importance of presence of family as a protective factor to improve all kinds of emotional and social skills.

\subsection{Family characteristics as Resilience Responses to UP's Risk Factors}

The resilience of individuals who live in UP is by great measure constructed within and through families. $66 \%$ of the articles which discuss this subject $(\mathrm{n}=18)$ emphasized family level responses and concluded that family is an element that can offer guidance, rules, discipline and structure to children and youth, and pinpoint the parents as those responsible for tackling family well-being [37]. Some authors state that independently of the individuality of coping responses towards UP [2,36,38], these responses are learnt and constructed through interaction with others (mainly within a household). This highlights the important role family has not only as a structure to satisfy needs, but as provider of possibilities towards psychological development and strengthening [38]. It is why in this category we focused on analyzing the individual's coping responses from the influence family has on them and in relation to the relationship the sample (mainly children and adolescents) have with their parent or guardian.

Primarily, $66 \%$ of the total articles $(n=18)$ only described parental involvement as a constructing element of resilience [37, 41-42]. In a more specific way, $16 \%$ of them $(n=4)$ mentioned active supervision and parental participation in regard to key points and decisions in youth's life $[3,31,48,50]$. As to the quality of the relationship, $13 \%(n=3)$ of the articles talk about the 
protection youth feels given by a secure form of attachment to their parents. They also make observations about the role extensive families and other adults have in the development of a resilient response to UP $[3,34,48]$.

The highest impacting element in generating resilient responses is family functioning (operationalized in many different ways). In relation to this theme, 3 articles mention family cohesion and mutual support [31, 33, 41]. These authors report that these family conditions influence youth self-esteem and self-efficacy. As a part of family functioning, routines and organization together with a consistent discipline were reported as characteristics pertaining to resilient families [30, 31, 37]. With a lower frequency but nonetheless highly significant to the samples, other authors referred beliefs and spiritual life as a crucial element in developing a resilient response towards UP [7, 42].

Families can be educators of resilient models of behavior [24]. Similarly, others studies described how in families coping skills [20,34], impulse control [42] and problem-solving skills are learnt [8]. These studies affirm that resilient attitudes learned within families let them an active involvement to try to get out to UP.

Finally, within this same theme, some studies propose the concept of family resilience $[8,37]$ in which family not only teaches children to be resilient, but the family itself as a coordinated amalgam, responds resiliently to the UP condition. In this sense, resilience is understood as a moderator or mediator between the environmental stressors and the behavior/result of the individuals. In particular, one study proposes to understand resilience as a process and not necessarily as a mixture of individual characteristics [42].

As we reported individual elements that were found to inhibit or weaken resilience, we also found family phenomena that made members of a family and families as a whole, more vulnerable and therefore less resilient. The most frequent (13\% of articles) of these is domestic violence $[30,35,49]$, whether it was presented as conjugal violence of child abuse and/or maltreatment. As to family functioning, permissive of authoritarian parental practices resulted in lower levels of resilience, but could be reverted once the father-child relationship was worked in terms of involvement, attachment, communication, and confidence [34]. Three more papers reported divorce as a factor with a negative role in the development of resilience [24, 35, 49]; on the other hand, the remaining two articles found that low family expectations were also related to low resilience $[30,33]$.

\subsection{Individual Resilient Responses to Urban Poverty}

Just over half $(51 \%)$ of the reviewed articles $(n=14)$ emphasize that resilient behaviors to face poverty are an individual-level expression. Most of them concluded that although resilience is an individual response, these responses are constructed from a family environment that includes: family support, supervision, clearly stated rules and discipline (also addressed as family structure) and a sense of belonging characterized by a strong social and community cohesion $[2,31,34]$, which clarifies how family structure makes a difference in what is learned as a response to vital difficulties. In this sense, resilience is taught and passed down by adults to younger generations.

Out of the reviewed articles, $6(22 \%)$ use the generic term identity (from cognitive structure) or self-esteem as a mediator of resilient response [31-32, 34-35, 49]. An individual's identity is constructed from the results and feedback received by performing certain actions, interacting with the environment and others. In this sense, identity refers to the way in which the person perceives him/herself, being positive or negative and the magnitude with which it values and recognizes its capabilities for determined tasks in response to UP. They emphasize that the self-esteem is the base to generate other type of responses of positive coping such as self-confidence or certainty in whatever the person decides to do.

Self-efficacy is another variable that integrates identity, although understudied; it favors the response of facing adversity $[8,32]$. Above all, in the education domain, assertiveness makes youngsters more resilient [40]. In the same sense, it appears that intellectual capacity also contributes in a direct form to express adaptive responses in front of the adversity, in those that live in UP. Firstly, cognitive maturity $[20,40]$ is reported as a protective factor against urban poverty. In particular, the ability to solve problems $[8,24]$ logically contributes to produce positive results regardless of adversity. Other personal expression variables that affect resilience in a context of poverty include creativity, humor and autonomy [45]. Therefore, if an adaptive behavior will be characterized by motivation to act, it would value any kind of achievement [24], tolerate frustration [40], and manage adversity with a sense of humor [41].

Another element of identity related to resilience is locus of control, better known as the ability to control impulses in light of frustration, generating with it an adaptive response of tolerance. The way in which the person perceives being the sole responsible actor of his/her action relates to positive attitudes towards the future [21] and autonomous ways of thinking and acting [45], which can aid in overcoming adversity.

Within the variety of individual responses, other authors identified empathy [8, 45], leadership [44] and conflict resolution skills [24]. Three cognitive capabilities of great value that contribute to respond to the condition of poverty. Very few authors drew their attention towards emotions as coping skills. One study found that fear of adverse results leads individuals to remain in a vulnerability state [41]. In case of depression was associated with low or absent resilience [33]. In this same group of people, anxiety was also reported by other study 
[49] and just one article referenced close relationships and the failure to make them as a factor that weakens resilience. In the field of motivation, one study has demonstrated that low levels of ambition were associated with low resilient individuals [32]. Tension or stress were reported by various authors as an inhibitor of resilience. In particular, PTSD [35, 43], and stress directly related to the conditions of poverty tend to reduce the probabilities of a positive response to adversity $[30,44]$. The negative impact of UP as a condition is observed in join others structural situations, for the same conditions of neighborhood violence and insecurity and reported such as victimization [8, 20, 31], sense of abandonment, exclusion or expulsion [2], stress or PTSD [35]. This last is a consequence of not only living in UP, but also experiencing a highly violent routine and possible abuse by third parties, in which the victim was seen immersed in a situation with little to none options to look after the individual's wellbeing and safety, which in turn generates a sense of extreme fear and vulnerability also referred as learned helplessness.

Generally, institutions, clinics and NGOs are those prepared to receive people in such conditions. It is common that, given their situation of extreme susceptibility, it is difficult to those living in UP to seek help and learn from others how to overcome such adversity. In these cases, it has been noticed that victims develop internalizing (e.g., anxiety, depression) and externalizing (e.g., aggression, violence) symptoms [2, 23, $33,39-40]$.

\subsection{Community Cohesion as a Protective and Resilience Factor in Response to UP}

One study emphasized that social resources (without considering availability or accessibility) aid the individual in producing positive results in adverse situations [40]. Being that other author emphasizes how the resource network will be different in relation to the individual's perception of received social support and the perception of such. All these social and government support configurations are related with a higher social resilience in individuals that live in UP [49].

Seventeen articles of the total pool $(62.9 \%)$ mentioned community as a protective factor, observing aspects that conform community itself and how they influence the individual resilient response. The majority of these 17 describe the importance of analyzing the order that exists in the community which can range from physical disorder, social disorder [23] and/or community/neighborhood violence $[3,30,33-34]$. The impact community as a risk factor might have on youth and identifies: gangs, drug use, vandalism and delinquency, disruptive behaviors and sexual risk behaviors [48]. In special, some peers, neighbors, classmates and family members might become a negative influence $[23,33,44]$, but the same time these last can function as protective factors among them. When they share the necessity to do more to reduce the violence in their community, then they organize in groups of community work or decided to participate more in activities that exist there. The best protective factor in community is the collaborative networking among them (the families).

\subsection{Positive Social Settings in Communities: Schools and Faith-based Institutions}

To this group of authors who speak about community, institutions such as churches and schools are part of the community and therefore, engaging in social organizations or churches $[21,24]$ and engaging with positive peers $[3,8,34,41]$ are elements that promote socially favorable behaviors in communities with high levels of social disorder.

In the school setting, research found that school might be a positive element for children living in UP [33, 48]. Schools would be positive if teachers were involved in the supervision and daily monitoring of students and also if they became role models for youth. Besides the teachers, a couple of studies highlight the relevance of individual characteristics in teenagers that live in UP and indicate that internal motivation, academic achievement which were measured as grade point average, involvement and active participate in scholar activities are considered resilient characteristics and provide youth with an opportunity of different life conditions in the future [23, 31]. However, others studies found negative effects of the school setting, as the behavior problems presented by teenagers predicted drug use, engaging in delinquency and low grade point average [34, 42].

The church as a faith-based institution also is mentioned as an important component given that religious practices [34] and religious coping strategies [35] contribute to strategies implemented to overcome the condition of UP. These articles conclude that practicing a religion, having a positive religious coping, having hope in God's will or believing God does not abandon believers were considered resilient characteristics to individuals living in UP.

\section{Discussion}

UP is a manifestation of inequality that has repercussions across myriad aspects of people's lives: physical, economic, social, personal, familial, residential, and communal. Urban poverty is common around the world and is something that individuals must cope with daily. This systematic literature review sought to identify how resilience can reduce some of the harmful consequences of urban poverty. The articles varied substantially on how they operationalized resilience: just 
two articles did it directly, and the rest utilized indicators from individual, family or community variables, as they worked to characterize the subjective and emotional wellbeing and relationships of the people experiencing UP. While addressing the root causes of UP will take substantial time and effort at a system level, psychological skills and resilience are one way to reduce the inequalities that emerge as a result of experiencing UP. Change can happen at the individual, community, and/or system levels; we encourage using a socioecological approach to work towards change at all of these levels simultaneously. We make recommendations accordingly. In this section, we discuss our main findings.

\subsection{Research Questions of Interest}

In response to our first research question, we identified the risk factors that limit and increase resilience for those experiencing UP. Resilience can be seen as a response to stressors present in a condition of social and economic disadvantage $[1,2,7-8,24,30-32,35,37,44,50]$. Organizations and government agencies can help promote resilience so that people experiencing urban poverty do not also have to singlehandedly tackle the additional task of building resilience. Resilience is seen as an adaptive behavior that includes learning from: one's own and other role model's experience in a family setting [8, 37, 42], community setting [32-33, 36] and/or from interventions tailored to develop socially expected behaviors and life skills [24, 42, 44] in comparison, a non-resilient response might negatively affect an individual cognitively and/or emotionally $[6,43]$. For example, developing community-driven interventions that include people experiencing urban poverty in the leadership team can promote desirable social and positive values. Such interventions could also have a youth-driven component to increase the self-confidence of children. These activities will improve their self-esteem to plan a life in which they can be resilient to UP and break the cycle of poverty.

Regarding our second research question of how UP and resilience interact to affect psychological development and functioning, our review is able to provide a preliminary response, but more research will be needed. Although the review did not provide a delimited and precise response of behaviors, the family network was consistently reported to support an individual during difficult times, provide discipline and supervision in order to orient youth into conflict solving and act as a mediator towards community support and a sense of belonging in an environment that reinforces resilient responses [2,31,34]. This allows us to see how family structure makes a difference in that what the individual learns as a response towards vital hardship. In this sense, it appears that resilience is taught by adults to youth and so requires spaces and opportunities for children and adolescents to interact with parents, teachers, and other adults who can serve as role models. With children, we encourage building a positive sense of self, by recognizing all kinds of academic and daily achievements. The goal is to promote in them confidence toward that can open all kind of conversations or ask for guidance without feeling judged.

The most common differences in the presentation of resilient responses towards UP can be seen by age group, as children and adolescents reported higher resilient responses than adults. According the resilience definition as a construct that includes all those behaviors and skills that drive the individual to positive results about adversities $[1,2]$, therefore being resilient can reflect a conscious and mature mental state after experiencing hardship [5]; in this sense, individuals are being resilient every time they face a situation of vulnerability. A variety of mental skills, including humor, empathy, creativity and autonomy, favor the handling of the emotions and behaviors of economic or social limitations (described as frustration, violent behavior, deviant or illegal behavior and internalizing symptoms) [20, 23, 33, 40, 43-45].

The most commonly reported risk factor in the UP environment from the studies reviewed was community social disorder with exposure to diverse forms of neighborhood violence; 2016) [31, 33, 35, 43-44]. This was also mentioned as an adverse background condition $(\mathrm{ABC})$, although a traditional view in psychology portrays an $\mathrm{ABC}$ as an occurrence in the life cycle of an individual that has a negative impact during a critical period. As to $\mathrm{ABCs}$, the most mentioned (even though they were not necessarily inclusion criteria for any study) were: divorce, single parent households, relationship quality and communication between parents and children, well-being, inadequate parenting skills characterized by poor discipline, supervision and low warmth [20,23, 31, 35, 44-45, 48]. Social workers may be able to help with individual-level change, and non-governmental organizations and government agencies can also play a role to address the community-level forces like neighborhood violence.

Risk factors threaten an individual's security and compromise their emotional stability, psychological well-being, and social functioning. They also put the person's response capabilities to the test by engaging their psychological structure and problem-solving skills. This places individuals who experience UP in a vulnerability condition that in turn puts at risk their psychological integrity, exposing it to any outcome and a lower probability to engage in a resilient response. By experiencing this condition repeatedly, this pattern culminates in a tolerance or resignation relationship that some authors named habituation, but that we identified as a circular relationship between UP and resilient behavior.

The articles reviewed suggest that consciousness, involvement, and social engagement can be good ways to motivate and enforce self-regulation and recover the control over inequality situation due to UP. Up to this point, the risks and indicators of resilience in these articles were 
visualized. Risk factors generally hinder coping skills because they jeopardize the resources of the individuals that experience them and many times, and actors do not question themselves as to whether they should or could leave the context of UP that has these factors. Resilience is understood as a protective factor; its impact generates adaptive behaviors when it interacts with the risks presented by the UP context. Interventions could promote emotional intelligence and control impulses, perhaps in school-based settings. This could include creating family-school partnerships.

The review showed that there is a relationship between risk and protective factors as if it were a tightrope. The relationship between UP and resilience is seen as cyclical and bidirectional, in which each affects the other, and socioecological, such that community and family factors can affect individuals and vice versa [7]. Given the complexity and diversity of psychological skills, behaviors, capabilities, beliefs and emotions, measuring UP's effects on resilience and the role of risk and protective factors can be challenging.

As pertaining to cognition, self-esteem is the most important base of the resilient response [31-32, 34-35, 45, 49], and a seed that generates other types of positive coping responses such as self-confidence or certainty in whatever the person decides to endeavor in: self-efficacy and cognitive maturity (also referred to as intelligence), problem solving skills, impulse regulation [8, 24], flexibility and autonomy [45].

The family plays an essential role in an individual's development of more resilient coping responses (as it was seen in academic achievement or behavior in school contexts throughout the samples). Specifically related to UP, family offers diverse protective factors, but the most important is the consciousness in address to improve behavioral self-control and achievement motivation. Families can direct individuals towards the spectrum of resilient responses such as: system of beliefs, development of morals, sense of spirituality, values, problem solving strategies, organization, discipline, structure oriented to develop self-control. This spectrum will be used in the future to prevent socially deviant behavior, psychopathology, social dysfunction and keep him/her in line with a more active role towards development and growth.

\subsection{Implications for Future Research}

We recommend that future researchers study how people experiencing UP make sense of their experiences, since economic and social inequalities make many of these experiences intractable, but there are still possibilities for thriving. Researchers could also explore how interventions at the family and school levels can build communities of resilience and lead to better well-being for all family and community members. The quality of the relation between
UP and resilience is determined for the consciousness level which define limit and capacities to response in the person. Independently belonging to one family or any other social group and of adversity in the context, all people and families have resources to cope it. This means that skills, attitudes, beliefs, values, and emotions, in subjective terms as positive, creative, constructive and cognitive resources, can be considered as resilient ways to overcome UP adversity. They are learnt from the personal environments and other social settings, including parents, family members, community organizations, and more.

\subsection{Strengths and Limitations of Study}

Among the strengths of this literature review is a sentiment expressed in the popular phrase, "all ways lead to Rome". This means, although this research was as objective general to know the relationship between UP and resilience, the scarce articles about that, our analyzes were more toward to explore the resilient indicators and responses in UP context. Most of the articles reviewed were made considering samples in poverty conditions and selected because they had received any helping from the government. Then, these articles emphasized, in different ways, the resilience, as the best skill to cope with UP, and offered lots of possible approaches to do so. The main limitation of this study was that for the most of articles, only one aspect of resilience was measured, and resilience was often measured in different ways. Our review sought to integrate across those studies so that we could build the perspective expressed here. Nevertheless, it helped us to establish some bases for the intervention because working over this kind of resilient indicators, we can improve conscientious in this population and motivation for they can find the change. Definitively, our intention with this paper never was to secure that de UP people ever find to escape from it, only to observe the spectrum of possibilities according to our pool of articles. The change begins with intrinsic motivation and it is centered in the person, from his or her cognitive resilient capacities.

\section{Conclusions}

Resilience is a dynamic construct that can be a useful resource in addressing the adversities linked to UP. The family and the community, through peer relationships, offer promising settings to support the development of resilience. In particular, in the family context, their member build and develop resilient skills, attitudes and thought. It is responsible of giving them secure, confidence, strengthen to move around their neighborhood, community, learning ones of the others at the same time they can involvement and participate in its organization. The results of this literature review let us to see that the urban poverty places are spaces with less social order (security, cohesion, 
public services, etc.). While the family has a big background the possibilities to cope UP condition, in terms of psychological and cognitive resources, they could not have had control over such distal and proximal structural stressors into UP context. Therefore, we also encourage people to work at the systems level to address the structural factors that affect UP and that cannot always be overcome by resilience. We encourage researchers and practitioners to develop interventions at the individual, family neighborhood or community, and systems levels to increase well-being among people experiencing urban poverty and promote the healthy development and social adaptation of all people.

\section{Acknowledgements}

This work was supported by the National Council of Science and Technology and the Universidad Iberoamericana's Research Department (PI Mireya Vilar-Compte). The authors would like to thank the women and men who participated in the study; students Paulina Rigual Solis, Alexis Hazael González Aguilar, Josefina Aumann, Olivia de Jongh and Olga Isabel Alfaro Ramirez for assistance with data collection and entry.

\section{REFERENCES}

[1] R. LeVine, S. Dixon, S. LeVine, A. Richman, P. Leiderman, C. Keefer and B. Brazelton. Childcare and culture: Lessons from Africa. New York: Cambridge University Press, 1994.

[2] E. Rosenzweig and A. Wigfield. STEM Motivation Interventions for Adolescents: A Promising Start, but Further to Go. Educational Psychologist, 51(2), 146-163, 2016. DOI:10.1080/00461520.2016.1154792.

[3] M. Wang and K. Sheikh (2014). Does Parental Involvement Matter for Student Achievement and Mental Health in High School? Child Development, 85(2), 610 625, 2014. doi:10.1111/cdev.12153.

[4] N. Hill and D. Tyson. Parental involvement in middle school: A meta-analytic assessment of the strategies that promote achievement. Developmental Psychology, 45, 740 $-763,2009$.

[5] A. Bandura. Social foundations of thought and action: Social cognitive theory. Englewood Cliffs, NJ: Prentice Hall, 1986.

[6] R. Ryan and E. Deci. Intrinsic and extrinsic motivations: Classic definitions and new directions. Contemporary Educational Psychology, 25(1), 54-67. Doi:10.1006/ceps.1999.1020, 2000.

[7] J. Eccles and A. Wigfield. Motivational beliefs, values, and goals. Annual Review of Psychology, 53, 109 - 132, 2002 .
[8] M. Suizzo, J. Moran, E. Pahlke, Y. Marroquin, L. Blondeau and A. Martinez. Pathways to Achievement: How Low - Income Mexican - Origin Parents Promote Their Adolescents Through School. Family Relations, 61(4), 533-547, 2012. DOI: 10.1111/j.1741-3729.2012.007 27.x.

[9] J. Griffith, G. Joe, L. Chatham and D. Simpson. The development and validation of a Simpatia scale for Hispanics entering drug treatment. Hispanic Journal of Behavioral Sciences, 20, 468 - 82, 1998.

[10] I. Alonso, I. Motivación y aprendizaje en el aula. Santillana, Madrid, España, 2000.

[11] D. Camacho and A. Fuligni. Extracurricular Participation among Adolescents from Immigrant Families. Journal of Youth \& Adolescence, 44(6), 1251-1262. DOI: 10.1007/s10964-014-0105-z, 2015.

[12] E. Erikson. Sociedad y adolescencia, Siglo XXI, México, 2002.

[13] V. Casas Santin, G. Carranza Peña and A., Ruiz Badillo. Guía para la planeación didáctica en la Universidad. UPN Polvo de gis, México, 2011.

[14] C. Hardway and A. Fuligni. Dimensions of family connectedness among adolescents with Mexican, Chinese, and European backgrounds. Developmental Psychology, 42, $1246-1258,2006$.

[15] P. Esparza and B. Sanchez. The role of attitudinal familyism in academic outcomes: A study of urban Latino high school seniors. Cultural Diversity and Ethnic Minority Psychology, 14, 193 - 200, 2008.

[16] S. Plunkett, and M. Bamaca-Goomez. The relationship between parenting, acculturation, and adolescent academics in Mexican-origin immigrant families in Los Angeles. Hispanic Journal of Behavioral Sciences, 25, 222 $-239,2003$.

[17] N. Gil-Ramirez and A. Martinez-Chaparro. La gestión para el fortalecimiento comunitario ejercida por madres líderes en contextos de vulnerabilidad. Pensando Psicología, 7(13), 39-49, 2011.

[18] Wood G, Salway S. Introduction: Securing Livelihoods in Dhaka Slums. Journal of International Development. 2000; 12(5): 669-88.

[19] Pryer JA. Poverty and Vulnerability in Dhaka Slums: The Urban Livelihoods Study. Aldershot and Burlington, VT: Ashgate Publishing Ltd; 2003.

[20] D. McClelland. La motivación de logro, estudio de la motivación humana. España: Nancea, Madrid, 1989.

[21] N. Sia. Perceived social support, achievement motivation and academic achievement of rural adolescents. Indian Journal of Health and Wellbeing, 5(4), 452-456, 2014.

[22] E. Locke and G. Latham. Building a Practically Useful Theory of Goal Setting and Task Motivation: A 35-Year Odyssey. American Psychologist, 57(9), 705-717. DOI: 10.1037//0003-066X.57.9.705, 2002.

[23] K. Smit, C. Brabander and R. Martens. Student-centered and teacher-centered learning environment in pre-vocational secondary education: Psychological needs, 
and motivation. Scandinavian Journal of Educational Research, 58(6), 695-712. DOI:10.1080/00313831.2013. 821090, 2014.

[24] R. Chambers, L. Tingey, B. Mullany, S. Parker, A. Lee and A. Barlow. Exploring sexual risk taking among American Indian adolescents through protection motivation theory. AIDS Care, 28(9), 1089-1096. DOI: doi.org/10.1080/09540121.2016.1164289, 2016.

[25] Sameroff AJ, Bartko WT, Baldwin A, Baldwin C, Seifer R. Family and social influences on the development of child competence. In Lewis M, Feiring C. eds. Families, risk, and competence. Mahwah, NJ: Lawrence Erlbaum Associates Publishers; 1998: 161-185.

[26] R. Negrete Prieto y G. Leyva Parra. «Los NiNis en México: una aproximación crítica a su medición». Revista Realidad, Datos y Espacios. Revista Internacional de Estadísticas y Geografía, 4, 1 (enero-abril.), http://www.inegi.org.mx/RD E/RDE 08/RDE 08 Art6.ht, 2013.

[27] Q. C. Villalba. El concepto de resiliencia individual y familiar. Aplicaciones en la intervención social. Revista sobre Igualdad y Calidad de Vida, 12(3), 283-299, 2003.

[28] N. I. González Arratia López Fuentes, J. L. Valdez Medina y Y. Zavala Borja. Resiliencia en adolescents mexicanos. Enseñanza e Investigación en Psicología, 13 (1), 41-52, 2008.

[29] A. D’Orazio, S. D’Anello, G. Escalante, A. Benítez, Y. Barreat y L. Esqueda, L. Síndrome de indiferencia vocacional: Medición y análisis. Educere, 15, 51, 429-438, 2011.

[30] P. Andrade Palos e I. Reyes-Lagunes. Locus de control y orientación al logro en hombres y mujeres. Revista de Psicología Social y Personalidad, 7(1), 75-84.1996.

[31] R. Jessor, R. Risk behavior in adolescence: psychosocial framework for understanding and action. Journal of Adolescence Health, 12, 597-605, 1991.

[32] R. Torres, H. Ochoa, F. Ibarra and A. Ramírez. Acompañamiento de jóvenes ante situaciones de riesgo. Manual para profesores. ITESO, Guadalajara, México, 2008.

[33] M. Trianes, M. de la Morena and A. Muñoz. Relaciones sociales y prevención de la inadaptación social y escolar. Aljibe, Málaga, 1999.

[34] M. L. Torres Cruz and A. Ruiz Badillo. Motivación al logro y el locus de control en estudiantes resilientes de bachillerato del Estado de México. Psicología Iberoamericana, 20, 2, julio-diciembre, 49-57, 2012.

[35] L. O'Neal and S. I. Promotive Factors and 8Psychosocial Adjustment among Urban Youth. Child \& Youth Care Forum, 45(6), 947-961.

[36] J. Cuellar, D. Jones and E. Sterrett. Examining Parenting in the Neighborhood Context: A Review. Journal of Child \& Family Studies, 24(1), 195-219, 2015.

[37] C. Messing. Desmotivación, insatisfacción y abandono de proyectos en los jóvenes. Noveduc, Buenos Aires, 2009.

[38] Orozco NL, Covarrubias KY. Estudios sobre las Culturas Contemporáneas. 2013; XIX (38):141-167.
[39] I. E. Yalom. Existential psychotherapy. Basic Books, New York, 1980.

[40] Luthar SS. Vulnerability and resilience: A study of high risk adolescents. Child Development. 1991; 62(3):600-616.

[41] J. L Barbería. "Generación NI NI: Ni estudia ni trabaja", El País, México, 22 de junio de 2009.

[42] R. Viau. La motivation en contexte scolaire. Bruxelles: de Boeck. 2009.

[43] B. A. Greene and T. K. DeBacker. Gender and orientations toward the future: Links to motivation. Educational Psychology Review, 16(2), 91-120, 2004.

[44] H. P. Mandel and S. I. Marcus. The psychology of under achievement: Differential diagnosis and differential treatment. In I. B. Wiley (Series ed.), Wiley serieon personality processes. New York: John Wiley \& Sons. 1988.

[45] C. H. Dorantes Rodriguez. El proyecto de investigación en psicología de su génesis a la publicación. Universidad Iberoamericana, México, 2010.

[46] Banks N. Livelihoods Limitations: The Political Economy of Urban Poverty in Dhaka, Bangladesh. Development and Change. 2015; 47(2):266-292. DOI: 10.1111/dech.12219.

[47] Moser, ON. The Asset Vulnerability Framework: Reassessing Urban Poverty Reduction Strategies. World Development. 1998; 26(1):1-19.

[48] R. Tuirán y J. L. Ávila. (Octuber 23, 2018). Jóvenes que no estudian ni trabajan: ¿Cuántos son? ¿quiénes son? ¿qué hacer? Online Available: http://archivo.estepais.com/site/2 012/jovenes-que-no-estudian-ni-trabajan-\% $\% 2 \% B F c u a n t o s$ -son- $\% \mathrm{C} 2 \% \mathrm{BFquienes}-$ son- $\% \mathrm{C} 2 \% \mathrm{BFque}$-hacer/.

[49] A. Neumann, E. Barker, H. M. Koot and B. Maughan. The role of contextual risk, impulsivity, and parental knowledge in the development of adolescent antisocial behavior. Journal of Abnormal Psychology, 119(3), 534-545, 2010.

[50] J. S. Coleman, T. Hoffer and S. B. Kilgore. High School Achievement: public, Catholic, and private schools. Basic Books, New York, 1982. 